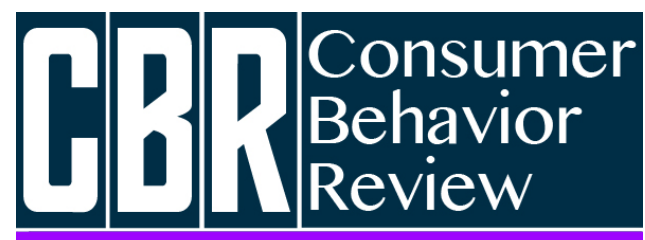

Revista Comportamento do Consumidor

Siqueira, J. L. S., Valdevino, A. M., Pellizzoni, L. N. \& Moraes, T. A. (2019). UBER: De carona no consumo colaborativo. Consumer Behavior Review, 3(1), 18-26.

ISSN: 2526-7884

Editor: Prof. Dr. Marconi Freitas da Costa Email da revista: cbr@ufpe.br

Avaliação: Double blind review

Recebido: 26 de novembro de 2018

Aceito: 16 de março de 2019

\title{
UBER: DE CARONA NO CONSUMO COLABORATIVO
}

\author{
José Lucas Silva Siqueira \\ Antonio Messias Valdevino \\ Lívia Nogueira Pellizzoni \\ Thiago Assunção de Moraes
}

José Lucas Silva Siqueira é Mestre pelo Programa de Pós-Graduação em

Administração da Universidade Federal de Paraíba - PPGA/UFPB. E-mail:

92lucassilva@gmail.com.

Antonio Messias Valdevino é Mestre pelo Programa de Pós-Graduação em

Administração da Universidade Federal de Paraíba - PPGA/UFPB. E-mail:

messiasurca@gmail.com.

Lívia Nogueira Pellizoni é Professora do Centro Universitário de João Pessoa -

UNIPÊ. E-mail:

livianogueira.adm@gmail.com.

Thiago Assunção de Moraes é Professor Efetivo da Universidade Estadual do Piauí UESPI. E-mail: thgmoraes@gmail.com. Esta pesquisa teve fomento da CAPES Coordenação de Aperfeiçoamento de Pessoa de Nível Superior. Os autores agracedecem aos avaliadores pelos comentários para melhoria do artigo.

\begin{abstract}
Resumo
Este estudo objetiva entender, no modelo de negócio da empresa Uber, como os colaboradores entendem o sentido de consumo colaborativo proposto pela organização. Dado que o modelo de negócio em estudo provocou uma disrupção no comportamento do consumidor, é imprescindível entender a visão do prestador do serviço, no caso o motorista, pois este também é considerado um consumidor pela empresa. Para tanto, foram realizadas entrevistas com motoristas que ofertam o serviço por meio do aplicativo, e realizando-se a análise interpretativa de seus discursos, concluiu-se que não há uma percepção, pelo menos não em sua totalidade, por parte deles do princípio colaborativo que deu origem ao negócio. A principal implicação gerencial se dá na mudança de visão que o negócio deve possuir dos motoristas, parceiros de negócio. Palavras-Chave: Consumo Colaborativo, Uber, Motoristas Parceiros.
\end{abstract}

Esta obra está licenciada com uma Licença Creative Commons Atribuição 4.0 Internacional.

\section{INTRODUÇÃO}

Em agosto de 2017 a Uber estava presente em 632 cidades do mundo, contando com mais de 50 mil motoristas e 13 milhões de usuários cadastrados no Brasil (Uber, 2017). A organização é considerada modelo de negócio diante de sua perspectiva tecnológica, e para alguns autores, como Villanova (2015), a Uber 
aparece como um exemplo de empresa que atua amparada pelos princípios do consumo colaborativo.

Desde sua fundação, a empresa envolveu-se em polêmicas, como discussões acerca do direito e da disputa com os taxistas (Zanata, De Paula \& Kira, 2015) e os escândalos envolvendo seu presidente, que à época, foi afastado (Ruic, 2017). Dentro dos entraves, as denúncias de assédio e a inflexibilidade da organização foram colocadas como pauta para discussão sobre a atuação da empresa no mercado. Além disso, colaboradores reclamavam da existência de valores que posicionavam a organização de uma forma autoritária, cheia de normas, regras e metas.

Botsman e Rogers (2011) afirmam que na modalidade de consumo colaborativo as pessoas optam pelos benefícios do acesso a produtos e serviços ao invés da propriedade. Tal preferência se justifica pela de economia de tempo, de dinheiro, de espaço, e de compartimento. Além disso, os autores defendem que a modalidade apresenta uma versatilidade do papel do consumidor que pode assumir o lugar de provedor. Assim, tendo com base a discussão inicial, esse trabalho busca responder à seguinte pergunta: como os motoristas da Uber compreendem o processo de consumo colaborativo?

Objetiva-se entender se, na percepção dos motoristas, a Uber compartilha dos princípios do consumo colaborativo, como denotado por alguns autores, a perspectiva aqui está sob a lente do fornecimento do serviço. Dessa forma, este artigo contribui e fomenta as discussões acerca do consumo colaborativo, utilizando uma das empresas de maior destaque no cenário internacional, com vistas a discutir se a mesma configura ou não um exemplo de consumo colaborativo sob a ótica de seus usuários, dado que o motorista também é um.

O trabalho está dividido em cinco seções, sendo a primeira esta introdução, seguida da revisão de literatura que apresenta breves sobre consumo colaborativo e sobre a Uber. Na sequência, delineia-se a metodologia do trabalho para que, em seguida, proceda-se a análise e discussão dos dados, com base na análise de conteúdo. Por fim, conclui-se o estudo, sintetizando os achados e apresentamse as limitações e sugestões de pesquisa.

\section{REFERENCIAL TEÓRICO \\ Consumo colaborativo}

A temática do consumo colaborativo, ainda não apresenta um consenso definitivo sobre definições teóricas. Belk (2014) entende essa forma de consumo como a coordenação da aquisição e distribuição de recursos, pelas pessoas, por alguma compensação, que por sua vez, abrange formas de compensações em que a troca e a negociação podem envolver pagamento e recebimento não monetário. Em outra concepção, Bardhi e Eckhardt (2012), em pesquisa sobre compartilhamento de carros, definem esse consumo baseado em acesso, ao invés de usar o termo compartilhamento utilizado no vocabulário cotidiano. No entanto, o acesso torna-se semelhante ao compartilhamento ao passo que as formas de consumo não envolvem transferência de propriedade.

Corroborando o acesso, Botsman e Rogers (2011), defendem que no consumo colaborativo as pessoas percebem os benefícios do acesso a produtos e serviços em detrimento da propriedade, economizam dinheiro, espaço e tempo e tornam-se cidadãos ativos novamente. Toda esta articulação está sendo possível por meio de redes sociais, tecnológicas e inteligentes que criam sistemas inovadores baseados no uso compartilhado.

Mohlmann (2015), dialogando com os julgamentos de Belk (2014), Bardhi e Eckhardt (2012) e Botsman e Rogers (2010), expõe que o consumo colaborativo ocorre em redes ou sistemas organizados em que seus integrantes exercem atividades compartilhadas por uma taxa ou compensação. Nesse sentido, esse tipo de consumo exclui as demais atividades de compartilhamento em que nenhuma recompensa está envolvida.

Em outra perspectiva, analisando o consumo colaborativo como fenômeno tecnológico e não apenas como uma cultura de consumo emergente, Hamari (2015), considera as atividade em que há a contribuição e o uso de recursos através de redes peer-to-peer, com adoção de tecnologias. Através do mapeamento de sites colaborativos, o autor, conceitua essa forma de consumo como a obtenção e concessão de acesso a bens e serviços pelas pessoas, coordenado através de serviços em comunidades. 
Os mercados peer-to-peer permitiram compartilhar recursos subutilizados como acomodação, ferramentas e passeios entre estranhos, e por isso, o campo da colaboração engloba muitos tipos de plataformas que diferem entre si pela forma do consumo (Huurner et al., 2017). Segundo os autores, a plataforma Uber, por exemplo, reflete uma situação de mercado tradicional em que se paga por um serviço no qual a relação entre os consumidores não é necessariamente importante. Não obstante, ratificando o trabalho de Botsman (2013), Huurner et al. (2015), definem essa economia emergente como um modelo econômico baseado na partilha de ativos subutilizados sem a transferência de propriedade, com benéficos monetários ou não, através de plataformas online. 0 cerne das mudanças dessa economia está no consumo colaborativo, que pode ser local e pessoal ou através de plataformas online na internet para conectar, combinar e encontrar algo ou alguém a fim de criar interações e trocas comerciais (Botsman \& Rogers, 2011).

Bardhi e Eckhardt (2012) observam, como motivações ao consumo colaborativo, que em vez de comprar e possuir coisas, os consumidores querem acesso ao bem e preferem pagar pela experiência de acessá-los por um tempo determinado. Mont (2004), afirma que apesar da tendência pela individualização e materialismo, as pessoas possuem necessidades sociais e de pertencimento a grupos ou comunidades que, ao longo dos anos, estão sendo substituídas por sociedades virtuais (Maurer et al., 2015).

Os exemplos de consumo colaborativo, apesar de variar em termos de escala, maturidade e propósito, compartilham princípios essenciais para seu funcionamento, como a massa crítica, capacidade ociosa, crença no bem comum e confiança entre estranhos (Botsman \& Rogers, 2011), conforme Quadro 1.

\begin{tabular}{|c|c|}
\hline Princípios & Descrição \\
\hline Massa Crítica & $\begin{array}{c}\text { Oferta de bens e serviços suficientes para que todos } \\
\text { tenham possibilidade de escolha e encontrem algo que } \\
\text { satisfaça suas necessidades }\end{array}$ \\
\hline Capacidade Ociosa & $\begin{array}{c}\text { Potencial de uso de determinados bens por outras pessoas, } \\
\text { quando o proprietário não estiver usando }\end{array}$ \\
\hline Crença no bem comum & Pensar em ações que reflitam em benefícios para o coletivo \\
\hline Confiança entre estranhos & $\begin{array}{c}\text { Familiaridade e confiança pessoas desconhecidas em } \\
\text { diferentes graus, de acordo com o contexto }\end{array}$ \\
\hline
\end{tabular}

Fonte: Baseado em Botman e Rogers (2011)

Quadro 1: Princípios de Consumo Colaborativo

Embora partilhe de alguns dos princípios e características dessa forma de consumo, discute-se o posicionamento da Uber quanto à classificação colaborativa. Existem alguns estudos que buscam identificar o consumo colaborativo por parte do cliente, todavia pouco se estuda sobre a perspectiva do ofertante. Dessa forma, busca-se verificar como os serviços prestados pelos motoristas parceiros da Uber são influenciados pelos princípios norteadores do consumo colaborativo apresentado no modelo de negócio.

\section{Uber}

A Uber é uma empresa norte americana que presta serviços eletrônicos na área de transporte privado urbano por meio de seu aplicativo em plataforma online. Fundada em 2009 por Garrett Camp e Travis Kalanick, a empresa começou como um aplicativo para solicitar carros pretos premium em áreas metropolitanas na cidade de São Francisco, Califórnia. Atualmente a malha logística das cidades está mudando para as cidades de todo o mundo, estando presente, além de São Francisco, em outras 632 cidades do mundo (Uber, 2017).

Conforme Mendes e Ceroy (2015) a entrada da empresa no país causou diversos debates nos círculos sociais e políticos no país. Enquanto alguns setores alegam ilegalidade do serviço prestado através do aplicativo da Uber, outros 
defendem a legitimidade da atividade no ordenamento jurídico.

Com a entrada da Uber no mercado, o sistema de mobilidade urbana e o transporte individual de passageiro mudaram, tomando novos rumos e gerando novas demandas. Toda essa trajetória não está restrita apenas aos movimentos da própria empresa, elas afetam e são afetados por todo um conjunto de agentes indivíduos ou coletividade (Dal Bó, 2017). A era informacional repercute na realidade social e possibilita novas formas de relações de trabalho. Nessa realidade, a Uber define-se como uma plataforma tecnológica que por intermédio de aplicativos para smartphone propicia o encontro de motoristas e usuários interessados em compartilhar o uso do veículo subutilizado pelo proprietário (Teodoro, D'afonseca \& Antonieta, 2017).

Nesse sentido se despontam os princípios do consumo colaborativo. Para Silva, Paiva e Diniz (2017) não se pode ignorar a rápida ascensão de modelos de negócios orientados por esses tipos de princípios como a Uber. Villanova (2015) retrata a Uber como um modelo de compartilhamento de carro peer-to-peer. Conforme Barros (2015), a dinâmica da Uber ocorre como tantas outras de consumo colaborativo, mas se destaca nesse cenário pela intensidade das críticas, manifestações e protestos dos quais vem sendo alvo.

Apesar das divergências nos trabalhos acadêmicos quanto ao pertencimento ou não da Uber como serviço pertencente aos modelos de negócios colaborativos, diversos trabalhos corroboram a ideia do princípio e o modelo começa a ser fonte de um vasto repertório de estudos, principalmente comparativos ao modelo vigente: os táxis, bem como a comparação destes com o Uber e a atuação do motorista na promoção da qualidade do serviço para que satisfaça a expectativa dos consumidores (De Moraes, Freire, Bachmann \& Abreu, 2017). Todavia, diante do posicionamento da empresa, e em meio a tais discussões, questiona-se aos motoristas como eles percebem a Uber sob a perspectiva do consumo colaborativo. É a esta questão que este artigo busca responder, partindo da perspectiva do ofertante, os motoristas da Uber.

\section{MÉTODO}

Para atender os objetivos da pesquisa realizou-se uma pesquisa de abordagem qualitativa, de cunho interpretativista que conforme diz Pratt (2009) se trata de uma tipologia de pesquisa que permite responder questões sobre "como" acontece alguma coisa, além disso, possibilita o entendimento de um fenômeno a partir da perspectiva dos "informantes". Quanto à natureza de aproximação do fenômeno a pesquisa é indutiva.

Procura-se, então evidenciar como os motoristas da Uber interpretam e entendem a empresa sob a perspectiva dos princípios colaborativos destacados por Botsman e Rogers (2011) Silva, Paiva e Diniz (2017), Villanova (2015), Barros (2015) entre outros. As técnicas utilizadas no estudo foram observação direta dos acontecimentos e entrevistas às pessoas envolvidas. Neste estudo as técnicas foram utilizadas com 8 motoristas parceiros da Uber, conforme Quadro 2.

\begin{tabular}{|c|c|c|c|c|c|}
\hline Nome & Gênero & Idade & Escolaridade & $\begin{array}{c}\text { Tempo de } \\
\text { atuação }\end{array}$ & $\begin{array}{c}\text { Outra } \\
\text { atividade }\end{array}$ \\
\hline Motorista 1 & Masculino & 34 anos & $\begin{array}{c}\text { Pós-graduação } \\
\text { incompleta }\end{array}$ & 3 semanas & Não \\
\hline Motorista 2 & Masculino & 52 anos & Ensino Médio & 11 meses & Sim \\
\hline Motorista 3 & Masculino & 41 anos & $\begin{array}{c}\text { Superior } \\
\text { anos e 5 } \\
\text { meses }\end{array}$ & Sim \\
\hline Motorista 4 & Masculino & 35 anos & Superior incompleto & 6 meses & Não \\
\hline Motorista 5 & Masculino & 72 anos & Médio & 6 meses & Não \\
\hline Motorista 6 & Masculino & 45 anos & Fundamental & 8 meses & Sim \\
\hline Motorista 7 & Masculino & 36 anos & Médio & 4 meses & Não \\
\hline Motorista 8 & Masculino & 36 anos & Médio & 8 meses & Não \\
\hline
\end{tabular}

Fonte: Dados da pesquisa (2017)

Quadro 2: Perfil dos entrevistados - motoristas Uber 
As entrevistas foram conduzidas presencialmente, por meio de roteiro semiestruturado, entre 16 e 23 de agosto de 2017. A escolha dos respondentes se deu de forma aleatória. Os motoristas, de João Pessoa (Paraíba), 5 ${ }^{a}$ cidade do Nordeste a receber o serviço, foram solicitados no aplicativo da empresa e as entrevistas tiveram condução durante o percurso, sendo que em algumas ocasiões houve a necessidade de estender o tempo da entrevista além do tempo da corrida.

$\mathrm{Na}$ maior parte das vezes o percurso era pequeno, cerca de $1 \mathrm{~km}$, desta forma, os custos para a pesquisa foram os menores possíveis, levando em consideração as taxas mínimas da Uber, bem como a taxa dinâmica (que se eleva de acordo com as demandas de solicitação), e giraram em torno de $\mathrm{R} \$ 65,00$ (sessenta e cinco reais), no total. As entrevistas foram cessadas quando se atingiu um nível de saturação dos dados (Glaser \& Strauss, 2017).

Após apresentação inicial e explicação dos objetivos da pesquisa, os colaboradores parceiros Uber foram submetidos às questões abertas que buscavam entender como eles se sentem em relação à empresa, e sua percepção sobre consumo colaborativo. Uma vez autorizadas, as entrevistas foram gravadas e em seguida transcritas, o que resultou em um arquivo de 25 páginas.

Os procedimentos de análise dos dados e discussão dos resultados foram realizados a partir das falas dos participantes, expostos Ipsis Litteris no decorrer desta pesquisa e triangulados com a teoria para que se responda ao objetivo maior deste estudo. Esta etapa da pesquisa foi realizada com a adoção da técnica de análise de conteúdo, descrevendo as categorias de motivações para ingresso na Uber e a percepção de consumo colaborativo pelos motoristas parceiros Uber (Bardin, 1977; Lofoland \& Lofland, 1995).

\section{ANÁLISE E DISCUSSÃO DOS RESULTADOS}

Os resultados desta análise serão interpretados e discutidos a partir das falas dos motoristas, buscando entender os fatores motivadores para os motoristas da Uber e os princípios colaborativos para tais motoristas.

\section{A Uber e as motivações e estímulos para os motoristas}

É possível destacar que os motoristas tenham suas motivações pessoais relacionadas à flexibilidade e dinamização que o modelo de negócio apresenta, como enfatizadas pelo motorista 2 , "esse negócio... você não ter patrão, você trabalhar no horário que você, que lhe convém, vamos colocar dessa forma". Outro aspecto a ser considerado é a oportunidade de trabalho e renda ofertada pelo modelo de negócio.

Desta forma, em alguns casos, o desemprego foi o fator que prevaleceu para os motoristas 1 , 4, 7 e 8. Os motoristas 3,5 e 6 viram a Uber como uma oportunidade de obterem uma renda extra com a empresa. Além disso, o motorista 5 enfatiza que "a cobrança e os valores são bem transparentes, o grau de segurança que existe entre um e outro, pelo fato de ambos serem cadastrados". Aqui, o conhecimento sobre o processo, reforça uma ligação entre o motorista e a empresa, pois a Uber dá ao motorista, por meio de seu aplicativo toda informação sobre a corrida, como trajeto, valor, tempo e, principalmente, quem solicitou o serviço.

0 Motorista 8 explica que parte da sua motivação veio de outros colaboradores Uber, que falam bem da empresa e acabaram motivando a também aderir a ela, necessitando, então, se regularizar para cumprir com uma necessidade da organização:

[...] o meu primo falou tanto por eu gostar de dirigir, aí ele disse que era bom tal, aí ele disse que ia mandar um convite [...] eu aceitei, aí eu fiz. $\mathrm{Eu}$ não tinha ainda função remunerada na habilitação, [...] aí eu fui no Detran, modifiquei, [...] e eu comecei a dirigir.

Em relação aos estímulos, a Uber oferece aumento de remuneração variável quando existe uma alta demanda pelos serviços. "O que ela faz é às vezes colocar uma taxa que se você for trabalhar você ganha mais. Ela vai coloca 1.1 da taxa da variável (aumento em torno de 10\%, no valor da corrida). Então é assim, uma forma de olhar um pouco pelo lado do motorista também", explica o motorista 3. Ele enfatiza que 
"ela coloca a taxa dinâmica pra que você seja compensado por aquele horário a mais que você vai trabalhar". Essa compensação por um horário a mais trabalhado, como explicado pelo motorista 3, pode ser entendido como um estímulo motivador presente na cultura organizacional da Uber.

É possível destacar o compensador financeiro oferecido pela organização para motivar o colaborador a produzir mais. Há, por parte dos motoristas, a percepção de que trabalhar mais pode gerar maior ganho de renda, o que evidencia que a empresa incentiva a produtividade para alcançar a demanda, isso atrai novos colaboradores, pois os que já atuam compartilham $o$ fato em conversas e depoimentos.

\section{Os princípios colaborativos para os motoristas da Uber}

Havendo a suposição de que a Uber assume uma postura colaborativista, conforme autores citados na seção anterior e na fundamentação teórica deste estudo, é válido acreditar que, pelo menos a priori, os princípios colaborativos estão presentes nas falas de seus colaboradores. Assim, buscou-se verificar as motivações em ser Uber pelos motoristas, dentre outras questões relacionadas à temática.

Retomando as discussões do pensamento colaborativo, Botsman e Rogers (2011) apontam que os exemplos de consumo colaborativo, apesar de variar em termos de escala, maturidade e propósito, compartilham princípios essenciais para seu funcionamento, como a massa crítica, capacidade ociosa, crença no bem comum e confiança entre estranhos.

Quanto aos princípios da massa crítica e da crença no bem comum, os motoristas enfatizam as possibilidades da prestação de um serviço mais barato que o táxi e mais seguro que um ônibus. 0 motorista 4 enfatiza o primeiro ponto afirmando "eu acho que a maior diferença mesmo é só o preço", essa fala pode ser confirmada no estudo de De Moraes et al. (2017), que ao comparar a qualidade entre os serviços de taxi e Uber utilizando a ServQual, constatou pouca ou nenhuma diferença na percepção do usuário quanto à aspectos como conforto e atendimento, por exemplo, mas sim uma diferença na percepção de preço.
0 motorista 2 explica que a "facilidade que o usuário vai ter, que é chamado de parceiro, vai ter, em ter o serviço, que é um serviço mais em conta, um serviço dito com melhor qualidade e alguns clientes confirmam". As falas dos motoristas estão mais atreladas a aspectos utilitaristas do que princípios colaborativistas.

Em relação à capacidade ociosa, como explica Botsman e Rogers (2011), pode haver associação ao bem a ser compartilhado, ao tempo, ao espaço ou à habilidade. Nesse sentido, os achados da pesquisa se põem em questões duais, uma vez que as motivações dos motoristas divergem. A maioria deles, ao decidir por colaborar com os serviços Uber, tinha uma necessidade pontual de renda, estavam em situação de ociosidade por estarem desempregados e viram na Uber uma possibilidade de ocupação.

A efeito de interpretação, é válido refletir se em uma condição em que não estivessem em situação similar, partilhariam de tal princípio. Ademais, em nenhum momento foi falado que, por exemplo, o carro não estava sendo utilizado ou teria a capacidade de ser utilizado de forma a transportar mais passageiros, mas sim, visto como uma possibilidade de lucratividade, atendendo uma finalidade econômica. Desta forma, pode-se perceber que o princípio colaborativista começa a dar espaço ao utilitarista, fala-se neste ínterim, em sim, um modelo de negócio.

A discussão apresentada anteriormente pode ser visualizada nas falas de alguns motoristas como: "foi esse lance do de você não ter o patrão, de você poder fazer teus horários, isso me levou a ser motorista Uber" (Motorista 2) ou "às vezes a gente faz uma corrida grande e $25 \%$ do que eles tiram, às vezes o ganho é muito pouco" (Motorista 3). 0 conceito de independência começa a ganhar força nos discursos quando a possibilidade de que o motorista pode configurar sua própria agenda de trabalho se faz um benefício, mesmo que os ganhos não sejam sempre satisfatórios em alguma corrida.

Já a confiança entre estranhos, para Botsman e Rogers (2011), se trata de uma confiança construída através da formação e desenvolvimento de comunidades descentralizadas e transparentes. Ter um aplicativo que compartilha informações com valores, trajetos, informações do usuário e do 
motorista é um processo que permite um nível maior de transparência aos serviços prestados pela Uber, como enfatizado pelo motorista 7. 0 motorista 4 fala que teve que vencer a timidez, o 5 diz que "estamos acostumados a lidar a todo momento com pessoas", o 3 e 6 diz que "sempre trabalhei com o público", que foram fatores que influenciaram nesse princípio.

Todavia essa confiança não acontece sempre, o motorista 1 explica que:

É perigoso viu [...]. Não é fácil, você não sabe quem você vai pegar. Então você não sabe para onde a pessoa vai, o problema é esse, você não sabe para onde a pessoa vai. Eu fico com medo, eu fico com medo. Eu peço a Deus para me abençoar. Mas eu fico muito com medo.

O caso acima mostra que o motorista apesar de não ter confiança, segue, ainda que com medo. Nesse mesmo contexto, o motorista $8 \mathrm{diz}$ que "às vezes a gente vai pegar uma pessoa, aí a pessoa não conversa e fica se escondendo atrás do banco, ai a gente já fica cismado de ser assalto", e são fatores que influenciam na desconfiança. Tais situações, descritas pelos motoristas 1 e 8 pode levar a atitudes mais severas, como a retratada pelo entrevistado 2 , onde explica que existem mecanismos que facilitam a escolha e/ou a desistência por uma corrida:

Eu procuro selecionar o cliente, às vezes eu [...] cancelo bastante, quando em determinado bairro eu não entro. Quando eu percebo, eu vou até o local, quando eu percebo que é lá dentro de determinado bairro eu procuro cancelar sem que o cliente tenha que pagar ônus por eu ter cancelado (Motorista 2).

A fala do entrevistado 2 apresenta outro ponto de benefício a ser destacado, que é a possibilidade de uma breve análise do perfil de quem solicitou a corrida. Isso considera o horário, local e destino, dando ao motorista a possibilidade de recusa da corrida e redução dos riscos. Essa possibilidade nem sempre é possível aos motoristas de táxis, por exemplo, e reduz a incerteza e a desconfiança. Dito isto, apresentando as discussões e falas dos motoristas da Uber, no que tange os aspectos colaborativos, pode-se dizer que ele não está presente na fala de alguns dos motoristas, pelo menos em sua totalidade. Pois é possível perceber que há uma série variada de motivações e formas de condução de rotina de jornada dos motoristas, enquanto colaboradores Uber.

\section{CONSIDERAÇÕES FINAIS}

0 estudo investigou como os motoristas da Uber percebem os princípios do consumo colaborativos, na prestação das atividades da sua ocupação enquanto parceiros da empresa. Quanto a isto, pode se percebe que em alguns casos os pressupostos teóricos diferem da realidade encontrada empiricamente.

Assim sendo, nem todos os princípios colaborativos foram encontrados nas práticas e nas motivações dos motoristas. Aqui, deve-se considerar que mesmo sendo o fundamento da origem do negócio da empresa Uber, a necessidade de uma renda determina a prática do motorista. Pode-se afirmar que a essência do consumo colaborativo não foi identificada nas falas dos motoristas, visão é de um negócio próprio ou uma fonte complementar de renda. Portanto, o que foi encontrado se trata de um quadro em que as necessidades pessoais, seja de ocupação e/ou renda se sobressaem. E, mesmo em alguns casos, os motoristas necessitando confiar, há a possibilidade concreta e muitas vezes executada de burlar o processo de confiança, cancelando uma corrida por exemplo. E isso, impacta nos outros princípios.

0 fator de insegurança se revelou presente nos discursos dado o desconhecimento que o motorista possui dos clientes e da característica que alguns bairros possuem de alto índice de violência. É um fator limitante da atuação e até mesmo considerado para efeito de abandono da profissão, fator também mencionado quanto aos custos de manutenção veicular, dado que o desgaste e a depreciação são maiores e as revisões mais frequentes, acarretando em maiores gastos com o veículo.

As limitações da pesquisa dizem respeito à dificuldade de conseguir realizar as entrevistas em horários que não fossem de trabalho para o motorista. Assim, as entrevistas estavam sujeitas, de maneira geral, a duração do tempo 
das viagens feitas, não permitindo aprofundamentos pois antes do término da viagem o motorista já havia recebido o chamado para uma nova corrida, e o tempo é considerado como recurso determinante na fórmula da renda do motorista.

Outra limitação refere-se aos recursos financeiros necessários para a coleta de dados, onde para executar as entrevistas foi necessário que se solicitasse a corrida em um trecho que contemplasse o tempo necessário para que a entrevista fosse completa. Recomenda-se para futuras pesquisas a realização de entrevistas que supram essa limitação, bem como, a utilização de outras abordagens sobre consumo colaborativo para diferentes verificações sobre a temática.

\section{REFERÊNCIAS}

Bardhi, F., \& Eckhardt, G. M. (2012). Access-based consumption: The case of car sharing. Journal of consumer research, 39(4), 881-898.

Bardin, L. (1977). Análise de conteúdo. Lisboa: edições, 70, 225.

De Barros, A. C. P. (2015). Uber: o consumo colaborativo e as lógicas do mercado. Congresso Internacional de Comunicação $e$ Consumo.

Botsman, R., \& Rogers, R. (2009). O que é meu é seu: como o consumo colaborativo vai mudar o nosso mundo. Porto Alegre: Bookman.

De Moraes, T. A., de Albuquerque Queiroga Freire, A., Bogoni Bachmann, T. H., \& Rodrigues de Abreu, N. (2017). Qualidade em Serviços e Dispositivos Móveis: Uma Análise a Partir da Aplicação do Modelo Servqual. Revista FSA, 14(4).

Bó, D., \& Julia, G. (2017). Perspectivas de empoderamento e de resistência em um modelo de economia compartilhada na ótica da teoria das transições: caso Uber no contexto brasileiro (Dissertação de Mestrado). Pontifícia Universidade Católica do Rio Grande do Sul.

Glaser, B. G., \& Strauss, A. L. (2017). Discovery of grounded theory: Strategies for qualitative research. Routledge.
Histórias... (2015) Uber apresenta objetivos e metas da empresa no Social Media Week 2015. UBER. Disponível em: https://goo.gl/pV5qHq Acesso em 20 de agosto de 2017.

Lofland, J., Lofland, L. H. (1995) Analyzing social settings: a guide to qualitative observation and analysis. Belmont: Wadsworth.

Maurer, A. M., Figueiró, P. S., Campos, S. A. P. D., Silva, V. S. D., \& Barcellos, M. D. D. (2015). Yes, we also can! O desenvolvimento de iniciativas de consumo colaborativo no Brasil. BASE: revista de administração e contabilidade da Unisinos, 12(1), 68-80.

Mendes, F. S., \& Ceroy, F. M. (2015). Economia compartilhada e a política nacional de mobilidade urbana: uma proposta de marco legal. Brasília: Núcleo de Estudos e Pesquisas/ CONLEG/Senado, Novembro/2015

Mont, 0. (2004). Institutionalisation of sustainable consumption patterns based on shared use. Ecological Economics, 50(1-2), 135-153.

Pratt, M. G. (2009). From the editors: For the lack of a boilerplate: Tips on writing up (and reviewing) qualitative research. Academy of Management Journal, 52(5), 856-862.

Ruic, G. CEO da Uber deixa posto indefinitivamente. Exame. (2017). Disponível em: https://goo.gl/4omkJk Acesso em 20 de agosto de 2017.

Silva, R. A., De Paiva, M. S., \& Diniz, G. S. (2017). Desafios jurídico-regulatórios e economia compartilhada: elementos para uma reflexão crítica. Scientia Iuris, 21(2), 98-125.

Teodoro, M. C. M., da Silva, T. C. D. A., \& Antonieta, M. (2017). Disrupção, economia compartilhada e o fenômeno Uber. Revista da Faculdade Mineira de Direito, 20(39), 1-30.

Uber. Nossa História.(2017).Uber. Disponível em: https://www.uber.com/pt-BR/our-story/; Acesso em 18 de agosto de 2017.

Villanova, A. L. I. (2015). Modelos de negócio na economia compartilhada: uma investigação multi-caso (Doctoral dissertation). Fundação Getúlio Vargas - FGV.

Zanata, R. A. F.; De Paula, P. C. B., Kira, B. (2015). Contribuições para o debate sobre regulação do aplicativo Uber no Brasil. InternetLab, Disponível em: https://goo.gl/sgu6PK Acesso em 20 de agosto de 2017. 


\section{UBER: Taking a Ride in Collaborative Consumption}

\section{Abstract}

This study aims to understand, in the business model of the company Uber, how the employees understand the sense of collaborative consumption proposed by the organization. Given that the business model under study caused a disruption in consumer behavior, it is essential to understand the vision of the service provider, in this case the driver, since the driver is also considered a consumer by the company. For that, interviews were conducted with drivers who offer the service through the application, and an interpretative analysis of their speeches was carried out, it was concluded that there is no perception, at least not in their totality, on the part of them of the collaborative principle which gave rise to the business. The main managerial implication happens in the change of vision that the business must have of the drivers, business partners.

Keywords: Collaborative Consumption, Uber, Partner Drivers. 